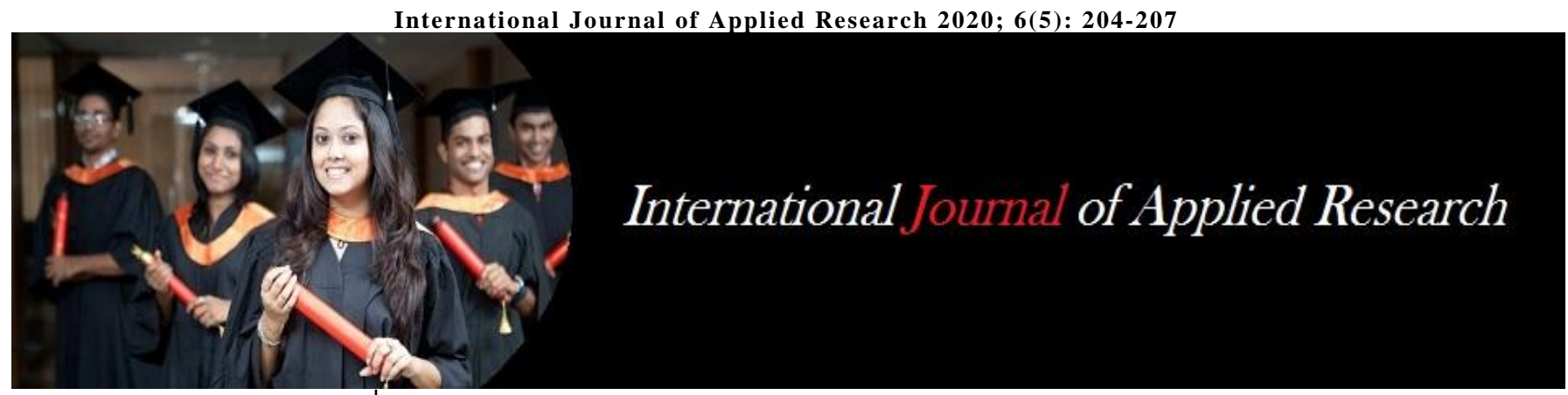

ISSN Print: 2394-7500 ISSN Online: 2394-5869 Impact Factor: 5.2

IJAR 2020; 6(5): 204-207 www.allresearchjournal.com

Received: 10-04-2020 Accepted: 12-05-2020

Oladimeji A.o.

Department of Agricultural and Bio-Environmental

Engineering Technology, Rufus Giwa Polytechnic, Owo, Ondo State, Nigeria

Imoukhuede O.B.

Department of Agricultural and Bio-Environmental Engineering Technology, Rufus Giwa Polytechnic, Owo, Ondo State, Nigeria

Ayodele B.B.

Department of Agricultural and Bio-Environmental Engineering Technology, Rufus Giwa Polytechnic, Owo, Ondo State, Nigeria

Corresponding Author: Oladimeji A.O.

Department of Agricultural and Bio-Environmental Engineering Technology, Rufus Giwa Polytechnic, Owo, Ondo State, Nigeria

\section{Design and construction of a multipurpose air screen grain cleaner}

\author{
Oladimeji A.O., Imoukhuede O.B. and Ayodele B.B.
}

DOI: https://doi.org/10.22271/allresearch.2020.v6.i6d.6783

\begin{abstract}
An air screen grain cleaning machine was designed and fabricated. The machine consists of the upper, the frame, the sieving unit, the blower, the outlet and the power unit. The machine was tested with a variable speed electric motor using three different grains (maize, soybean and melon) at three difference speed of 650rpm, 700rpm and 750rpm respectively. The results show that increase in the machine speed increases the machine capacity but reduces time of operation the efficient of the machine. The least efficiency of the machine was recorded to be $88 \%$ when maize was fed at 750rpm and joint highest efficiency of $94 \%$ at $650 \mathrm{rpm}$ when soybeans and melon were fed.
\end{abstract}

Keywords: Design, Construction, Multipurpose, Air screen, Grain, Cleaner

\section{Introduction}

Africa with its vast land area covering 3 billion hectares has 1.3 billion hectares of agricultural land out of which only 252 million hectares $(19.36 \%)$ is arable (FAO, 2011) ${ }^{[4]}$. Africa is the center of origin and also a major producer of several cereals like maize, soybeans, sorghum, pearl millet, Mellon, finger millet, and African rice. Maize has overtaken these traditional cereals while wheat is widely cultivated in North Africa and in Sudan and Ethiopia (Aremu et. al, 2015) ${ }^{[1]}$. Agriculture is the 'engine for growth' in Africa. With subsistence agriculture practiced by majority small holder farmers, yield gaps are high and poor soils, amongst other constraints add to the difficulties for sustainable farming and incomes. Cereals like Sorghum, Millets, Wheat, Maize and Rice are major staple foods of the most population. These cereals are grown over an area of 98.6 million hectares producing 162 million tons.

Post-harvest losses is one of the enemies of farmers as food lost from one stage to the other during handling (Oladimeji et al, 2019) ${ }^{[8]}$.

Reducing post-harvest losses in grain processing industries is an important step toward ensuring greater global food grain security as increased future demand will require increased production efficiency.

One of the handling processes of grains after harvesting is winnowing or air screening which is a process of cleaning chaff and other foreign materials from grains initially harvested from the field, and is conducted by using combination of screen and wind to separate or blow lighter chaff, debris and other foreign materials away from useful grains. (Okunola and Igbeka, 2009) [7].

Cereals are grains or edible seeds of the grass family, Gramineae (Bender and Bender 1999) [3]. Cereals are grown for their highly nutritious edible seeds, which are often referred to as grains. Some cereals have been staple foods both directly for human consumption and indirectly via livestock feed since the beginning of civilization (BNF, 1994). Cereals are the most important sources of food and cereal based foods are a major source of energy, protein, vitamins and minerals for the world population. Generally, cereals are cheap to produce, easily stored and transported, and do not deteriorate readily if kept dry (FAO, 2000) ${ }^{[5]}$.

Winnowing which is one of the unit operations of these grains 'maize, soybean and melon' and other grains, which involves manual removal of chaff by the use of tray or other traditional means. In this method, a sizeable quantity of the grains are placed in a flat tray, 
the tray are used to throw the grains up and received in other to expel its chaff. This process of winnowing is associated with the following shortcomings;

- Low capacity; the quantity of grains that can be processed using manual method is quite limited compared to when a machine is used.

- Time consuming; this method wastes useful time that would have been used in doing other jobs.

- Low efficiency of performance.

- The above constraint work against the continuous adoption of the manual method of removing the chaff from grains. Hence, the need to develop a machine that would be able to eliminate or reduced to the barest minimum all the above limitations associated with the manual method of removing chaffs and other foreign materials from grains.

\section{Design consideration of an air screen grain cleaner}

Properties of grains: The properties of grains such as weight, moisture content and types were considered in material selection and design.

Ease of operation: The machine was designed and constructed for the convenience of the operator.

Rigidity: The machine rigidity was considered while selecting relevant joining processes. Bolt and nut were used to fasten some parts, some were welded while some were machined to give concentricity for absolute rigidity.

Vibration Resistance: To prevent shaking of the component parts the machine was fixed on a well-designed frame network, pillow bearings were used to help the transmission of motion and minimize the effect of vibration and noise.

Durability: During the selection of the machine parts, properties like: Strength, corrosion resistance ability, machinability etc were considered so that the machine might last a long period of time before any sign of damage.

Cost: All materials used for the fabrication of this machine were sourced locally to reduce the unit cost of the machine.

\section{Design and Description of Machine Component Parts}

Hopper: This is a feed or channel through which the grains are fed into the screening machine. The hopper which consist of a feed gate for the control of feed rate is made up of galvanize metal sheet and it is trapezoidal in shape for better performance.

Frame: The frame is a part of the air screen machine on which all other parts and component are mounted. It bears the load of the machine. It also provides support for the machine during operation and when not in operation.

Bearing: The machine consists of a four pillow bearings placed between components of the machine to act as support and increase movement and reduce friction.

Screen: The screen or sieving unit which is made of galvanised sieving net are of three different types of a pair each and of different openings, each pair is design for different grain and the screens are removable.

Cleaning Unit: The cleaning unit is an enclosed fan with blades made from metal sheet arranged on a shaft and enclosed in housing. The fan produces the air blast that effects the separation of the chaff and unwanted materials from grains.

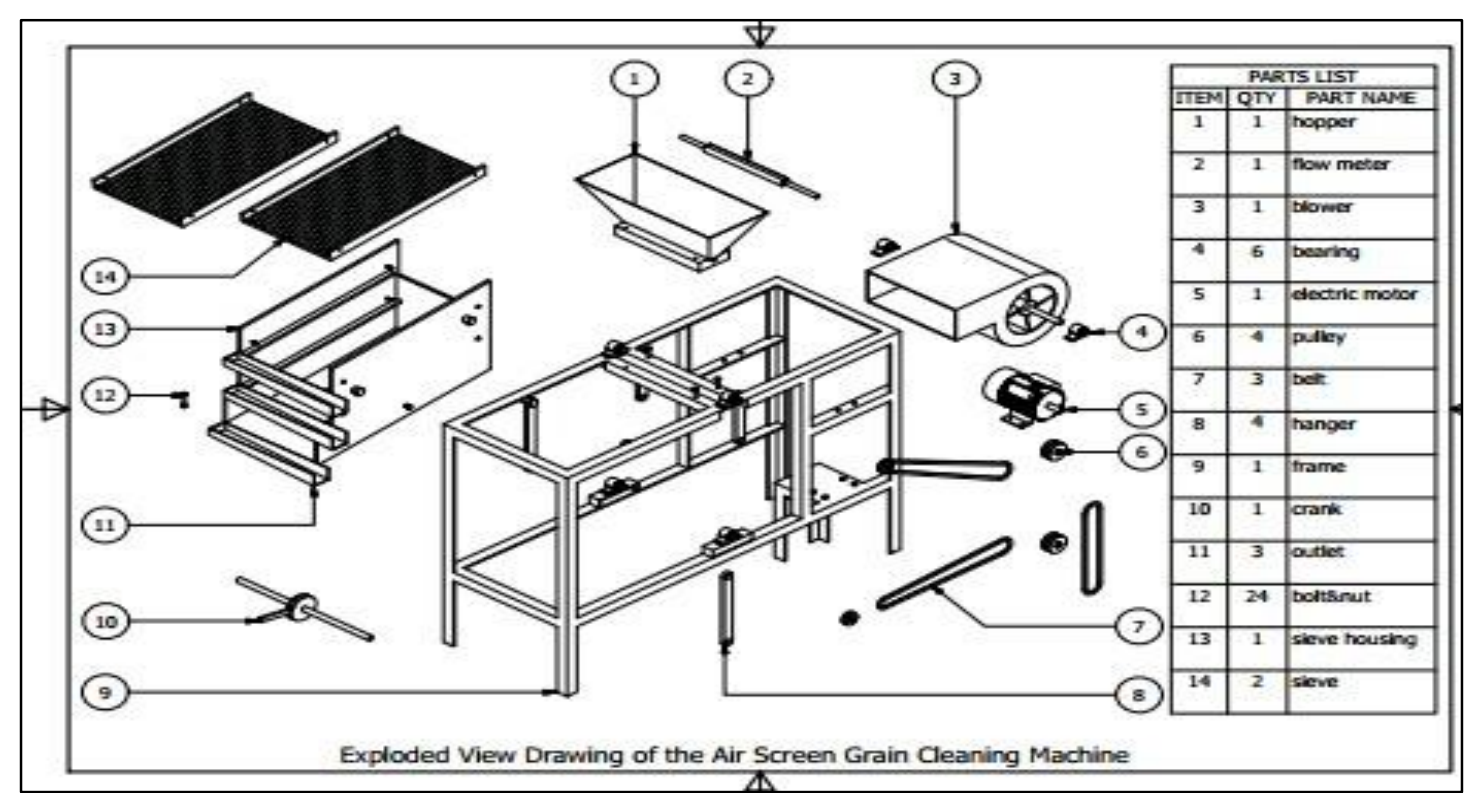

Fig 1: Exploded view drawing of the air screen grain cleaning machine

\section{Machine operation}

The air screen grain cleaning machine is operated through the cranking of the prime mover which drives the fan. An amount of threshed grains are fed into the machine through the hopper and a feed gate in the hopper regulate the flow of the grain into the machine (Feed Rate). As the grains flow down by gravity it falls across fan air stream unto the sieve.
The chaffs and other foreign materials that are lighter than the grains are blown out of the machine through chaff outlet. Other foreign materials that cannot be blown off are sieved through the openings of the sieve and are collected under the machine as the machine continues to vibrate, while clean grains are collected through its outlet. 


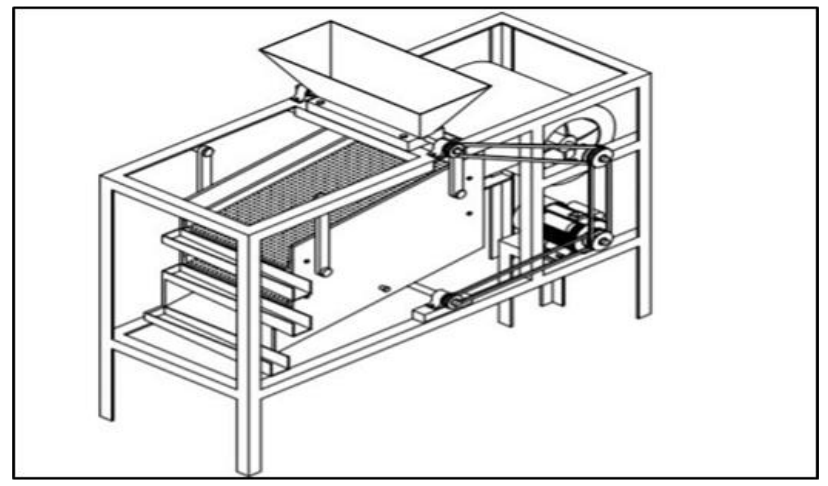

Fig 2: Isometric drawing of the multipurpose air screen grain cleaner

\section{Machine performance test}

The performance test of the multipurpose air screen cleaning machine was carried out at the fabrication workshop of Agricultural and Bio-Environmental Engineering Technology Department of Rufus Giwa Polytechnic, Owo, Ondo State, Nigeria. The machine was evaluated at varying speed of 650,700 , and $750 \mathrm{rpm}$ at a constant moisture content of $15 \%, 10 \%$ and $14 \%$ wet basis for maize, soybean and melon as reported by Sallih (2018), Timothy et-al (2016) [10] and Vertucci (1993) [11] respectively. The machine speeds were achieved by the use of a variable speed electric motor. The moisture content of each sample was determined using the method described by ASABE (2006) ${ }^{[2]}$. The machine capacity and cleaning efficiency were calculated using the following equations;

Machine Capacity $=\frac{\text { input weight }}{\text { Time taken }} \frac{\mathrm{kg}}{\mathrm{s}}$

Cleaning Efficiency $\%=\frac{w s}{w i} \times 100$

Where: Ws = weight of cleaned grains $(\mathrm{kg})$ and $\mathrm{Wi}=$ Initial weight of grains $(\mathrm{kg})$

\section{Results and Discussion}

The results of the performance test carried out on the machine are discussed based on following.

\section{Machine capacity}

Figure 3 below shows the effect of machine speed for different grains on machine capacity. From the figure, it can be seen that, for all the grains (soybeans, maize and melon), increase in machine speed leads to corresponding increase in machine capacity, that is, 650rpm,700rpm and 750rpm machine capacity lead to $98 \mathrm{~kg} / \mathrm{h}, 125 \mathrm{~kg} / \mathrm{h}$ and $143 \mathrm{~kg} / \mathrm{h}$ respectively.

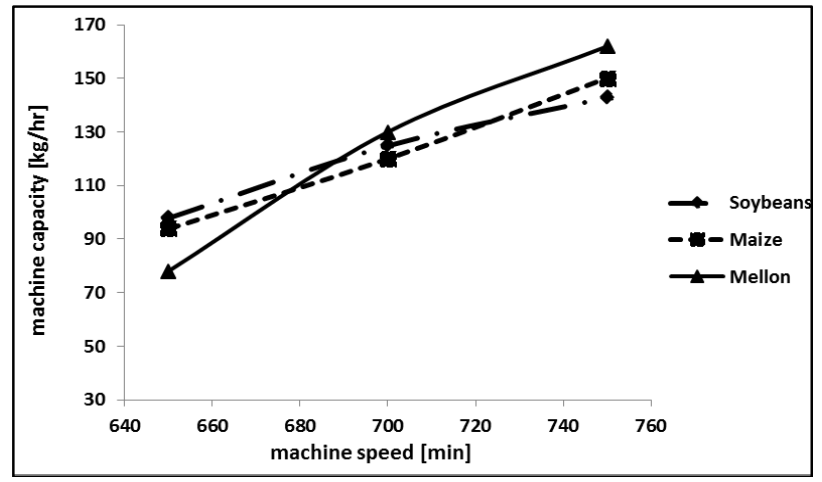

Fig 3: Effect of machine speed on machine capacity.
Time

Figure 4 below shows the effect of machine speed for different grains on time of operation. It can be seen from that figure that for all the grains, increase in machine speed result to reduced time of operation. This is due to more air blast that is available to blow away chaff from the grains as the speed increases.

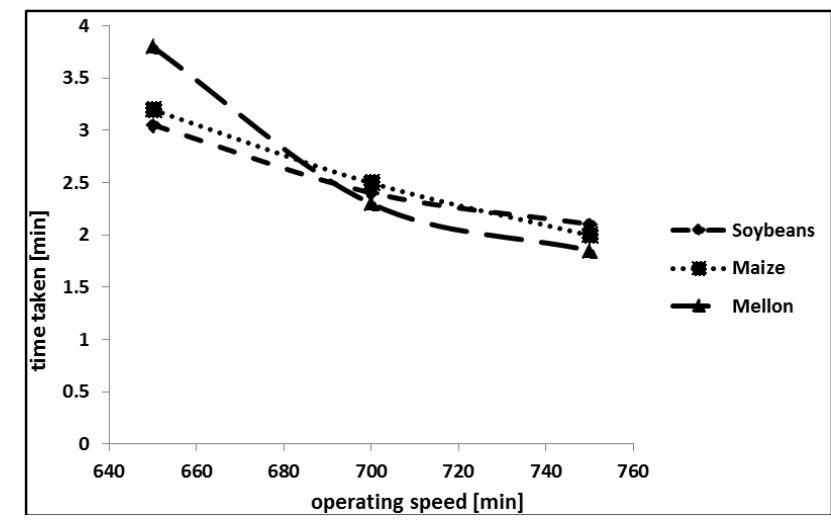

Fig 4: Effect of machine speed on time of operation.

\section{Machine efficiency}

Figure 5 below shows the effect of machine speed for different grain on the efficiency of the air screen grain cleaner. From the figure, it can be seen that increase in machine speed result to decrease in machine efficiency. At 650rpm, for soybean and melon, the machine recorded $94 \%$ efficiency, for maize, the machine recorded $93 \%$ efficiency, at 700rpm and 750rpm the efficiency was $83 \%$ and $89 \%$ respectively for soybeans; $93 \%$ and $88 \%$ respectively for maize and $92 \%$ and $90 \%$ respectively for melon. This mean that as the machine speed increases more air blast was available to remove chaff from the grains there is also increase in machine vibration to sieve the grains. At speeds 700rpm and 750rpm, the air blast was very high thereby blowing both chaff and some grains away during cleaning, therefore, more grains are been removed along side with the chaff which resulted to reduction in machine efficiency.

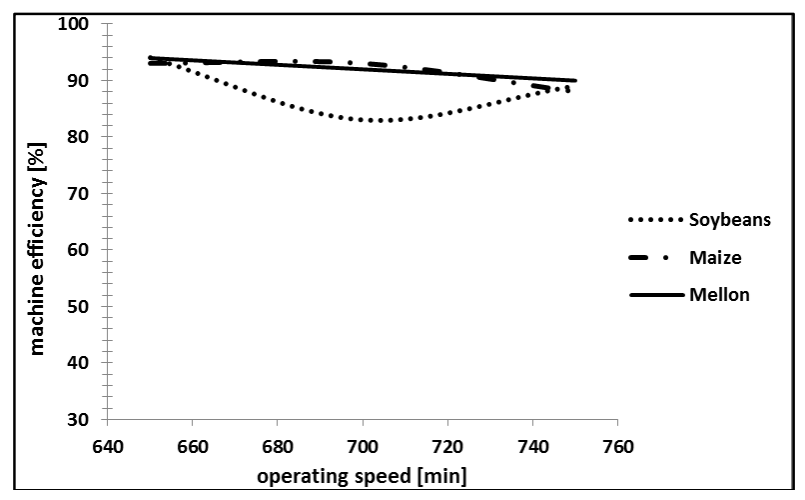

Fig 5: Effect of machine speed on machine efficiency

\section{Conclusion and Recommendation}

The air screen grain cleaning machine was designed and fabricated in Agricultural and Bio-Environmental Engineering Technology Department. Three different grains (maize, soybeans and melon) were used to carry out test on the machine at varied speed of 650rpm, 700rpm and 750rpm respectively.

The result of the machine shows that increase in speed increases the machine capacity and reduce time of operation 
of the machine but the efficiency reduces as the speed increases. The machine recorded least efficiency of $88 \%$ at 750rpm when maize was fed and highest joint efficiency of $94 \%$ at $650 \mathrm{rpm}$ when soybean and melon was fed. The variation in efficiency is as a result of high fan blast at 750rpm which blows both chaff and some grains away.

\section{Recommendation}

The machine "multipurpose air screen grain cleaning machine" is a simple and easy to operate one, it has economic advantages over other existing cleaning machine as it can be used to clean various grains and also fabricated from locally available materials. The adoption of this machine by our small and medium grains processors is encouraged as it will reduced the purchase of different machine for different grains.

\section{References}

1. Aremu DO, Adewumi IO, Ijadunola JA. Design, Fabrication and Performance Evaluation of a Motorized Maize Shelling Machine Journal of Biology, Agriculture and Healthcare www.iiste.org ISSN 22243208 (Paper) ISSN 2225-093X (Online). 2015; 5(5).

2. ASABE. ASAE 5368.2 moisture measurement in forages. IK ASABE, standard 608.st Joseph M.I,

America society of Agricultural and Biological Engineering, 2006.

3. Bender DA, Bender AE. Benders' Dictionary of Nutrition and Food Technology, $7^{\text {th }}$ edn. Woodhead Publishing, Abington. P. In 9th African Crop Science Conference Proceedings, 3-8. Cape Town, South Africa: African Crop Science Society, 1999.

4. FAO. Global Food Losses and Food Waste. Food and Agricultural Organization of the United Nations, Rome, 2011.

5. Food and Agriculture Organization of the United Nations, FAO, 2000. Tropical Maize

6. Improvement and Production. FAO Plant Production and protection series, No.28.

7. Okunola AA, Igbeka JC. Development of a reciprocating sieve and air blast cereal cleaner. Ed. Tenywa, J. S., Joubert, G. D., Marais, D., Rubaihayo, P. R., Nampala, M., 2009.

8. Oladimeji AO, Olajide OG, Abisuwa TA, Ayodele BB. Post Harvest Losses: Impact on Nigeria Economy. European Modern Studies Journal. 2019; 3(3). available at journal-ems.com

9. Salih K, Alwan Alsherifi. Affecting on threshing machine types, grain moisture content and cylinder speeds for maize, cadiz variety. CIGR Journal. 2018; 20(3).

10. Timothy Adesoye Adekanye, AdamsBlessing Osakpanwan and Idaosa Endurance Osaivibie,. Evaluation of a soybean threshing machine for small scale farmers. CIGR Journals. 2016; 18(2).

11. Vertucci CW, Roos EE. Theoretical basis for seed storage II: The influence of temperature on optimum moisture level. Seed Science Research. 1993; 3:201203. 